\title{
Molecular weight distribution and corrosion inhibitor activity of 4-vinylpyridine oligomer synthesized using low concentration hydrogen peroxide as the initiator
}

\section{Ilim, ${ }^{1}$ (i) $*$ R. Fitriani, ${ }^{2}$ T. Prabowo, ${ }^{2}$ S. Bahri, ${ }^{1}$ (iD R. Marjunus ${ }^{3}$ (i) and W. Simanjuntak ${ }^{1}$}

${ }^{1}$ Department of Chemistry, Faculty of Mathematics and Natural Sciences, the University of Lampung, Jl. S. Brojonegoro No 1 Bandarlampung, 35145 Indonesia

${ }^{2}$ Graduate Student of Department of Chemistry, Faculty of Mathematics and Natural

Sciences, the University of Lampung, Jl. S. Brojonegoro No 1 Bandarlampung, 35145 Indonesia

${ }^{3}$ Department of Physics Faculty of Mathematics and Natural Sciences, the University of Lampung, Jl. S. Brojonegoro No 1 Bandarlampung, 35145 Indonesia

*E-mail: ilim@fmipa.unila.ac.id

\begin{abstract}
Low molecular weight 4-vinylpyridine oligomer or O(4-VP) has been synthesized using $0.25 \mathrm{M}$ hydrogen peroxide as the initiator. The resulting $\mathrm{O}(4-\mathrm{VP})$ was characterized by Fourier transform infrared (FTIR) spectroscopy for identification of functional groups, and mass spectroscopy (MS) for determination of molecular weights. O(4-VP) was tested as a corrosion inhibitor of mild steel in a corrosive solution saturated with carbon dioxide using wheel test and electrochemical methods, i.e., electrochemical impedance spectroscopy (EIS) and Tafel plots. Mild steel surface analysis was performed by scanning electron microscopy (SEM). The product of the synthesis is a viscous orange compound. The mass spectrum showed that $\mathrm{O}(4-\mathrm{VP})$ had a mass $(\mathrm{m} / \mathrm{z})$ of $100-900$, which is in accordance with the chain length of 1-9 monomer units, where the chain length of 4 (tetramer) is the most abundant fraction. The FTIR results show no significant difference between the monomer and $\mathrm{O}(4-\mathrm{VP})$. The wheel test as a screening test showed that O(4-VP) exhibited corrosion inhibitor activity. This activity was confirmed by the results of EIS and Tafel analyses, which also demonstrated that protection increased with increasing concentration of $\mathrm{O}(4-\mathrm{VP})$ and temperature. At temperature $70^{\circ} \mathrm{C}$ and a concentration of $150 \mathrm{mg} \mathrm{L}^{-1}$, the protection by $\mathrm{O}(4-\mathrm{VP}$ ) reached $81.9 \%$ (based on EIS) and $87.8 \%$ (based on Tafel plots). Protection of mild steel was also confirmed by the surface morphology of the sample obtained by SEM characterization.
\end{abstract}

Keywords: 4-vinylpyridine oligomer, hydrogen peroxide, molecular weight, $\mathrm{CO}_{2}$ corrosion inhibitor, electrochemical method. 


\section{Introduction}

The use of corrosion inhibitors is one of the most cost-effective and flexible methods used to control acid corrosion including carbon dioxide corrosion [1-3]. The use of corrosion inhibitors to protect a metal began in the mid-19th century, while intensive basic studies of corrosion inhibitors and the factors that influence their effectiveness started about 50 years ago [3]. The development and research of new compounds as corrosion inhibitors, both organic and inorganic ones, continues today. It is known that heteroatomic organic compounds containing oxygen, phosphorus, sulfur, and nitrogen are able to function as very effective corrosion inhibitors in acidic medium [1-4].

Currently, polymer inhibitors constitute a group of compounds known to have activity as corrosion inhibitors that continues to be developed. As a corrosion inhibitor, polymers with certain functional groups have the ability to form complexes with metal ions on the metal surface [5]. Due to their large size, polymer molecules are able to cover a wider area metal, so that the metal surface is protected from corrosive components in the environment. In addition, the inhibitory power of a polymer is also supported by its structure, especially cyclic rings, and the presence of heteroatoms, especially $\mathrm{O}, \mathrm{P}, \mathrm{S}$ and $\mathrm{N}$. Because of their good performance, many polymer compounds containing heteroatoms have been investigated for their ability as corrosion inhibitors, especially vinylpyridine-based polymers [6-11] and vinylpyridine -based oligomers and their derivatives [12-15].

In the previous study, a (4-vinylpyridine) oligomer was synthesized using hydrogen peroxide as the initiator according to the Sciven method [16] to produce an orange viscous liquid having a mass $(\mathrm{m} / \mathrm{z})$ of $200-2400$ or equivalent with a chain length of 2-22 monomer units. The product was found to exhibit the ability to protect $\mathrm{CO}_{2}$ corrosion better at high temperature, where according to linear polarization resistance (LPR), the protection percentage of around $89 \%$ was achieved at $70^{\circ} \mathrm{C}$ and $15 \mathrm{ppm}$ inhibitor concentration [12] and [14].

The 4-vinylpyridine or $\mathrm{O}(4-\mathrm{VP})$ oligomer was synthesized by reacting 4-vinylpiridin monomer, methanol and distilled water solvents, and hydrogen peroxide $\left(\mathrm{H}_{2} \mathrm{O}_{2}\right)$ as the initiator [12]. Less $\mathrm{H}_{2} \mathrm{O}_{2}$ was used in this study compared to previous studies [12] so as to obtain the $\mathrm{O}(4-\mathrm{VP})$ compound with a lower molecular weight. This research was focused on synthesizing 4-vinylpyridine oligomeric compounds in order to obtain a lower molecular weight of 4-vinylpyridine oligomer by using a lower concentration of hydrogen peroxide initiator in the hope to achieve a better protection. The synthesized compound was characterized by Fourier transform infrared spectroscopy (FTIR) to determine the functional groups, and mass spectrometry (MS) to determine its molecular weight. The synthesized compounds were tested for their effectiveness as corrosion inhibitors of mild steel in a corrosive solution saturated with carbon dioxide by wheel test and electrochemical methods, namely electrochemical impedance spectroscopy (EIS) and Tafel Plot. The surface morphology of mild steel with and without the corrosion inhibitor was observed using a scanning electron microscope (SEM). 


\section{Materials and Methods}

\section{Materials and tools}

The materials used in this research are: 4-vinylpyridine, hydrogen peroxide $\left(\mathrm{H}_{2} \mathrm{O}_{2}\right)$, methanol, ethanol, $\mathrm{Sb}_{2} \mathrm{O}_{3}, \mathrm{SnCl}_{2}$, concentrated $\mathrm{HCl}, \mathrm{NaCl}$, distilled water, $\mathrm{NaHCO}_{3}, \mathrm{CO}_{2}$ gas, hydrogen gas, sandpaper with roughness sizes of 320, 400, 600, 800, 1000, and 1200, mild steel coupons, and cylindrical mild steel electrodes. The chemical composition of the mild steel was previously determined using spectrographic analysis, indicating that the sample is composed of Fe (98.87\%), C (0.22\%), Mn (0.74\%), Si (0.02\%), S (0.014\%), P (0.02\%), $\mathrm{Ni}(0.05 \%), \mathrm{Cr}(0.04 \%), \mathrm{Mo}(<0.01 \%), \mathrm{Cu}(<0.01 \%), \mathrm{Al}(<0.01 \%)$. The corrosive solution was prepared by dissolving $\mathrm{NaCl}(3 \% w / v)$ and $\mathrm{NaHCO}_{3}\left(100 \mathrm{mg} \mathrm{L}^{-1}\right)$ in deionized water. The equipments include a set of Voltalab tools (Pgz 301), EC-Lab V10.40 software, rotary evaporator, micrometer, analytical balance, micropipette, wheel oven, reference electrode ( $\mathrm{Ag} / \mathrm{AgCl}$ electrode), $\mathrm{Pt}$ auxiliary electrode, thermometer, magnetic stirrer, water bath, FTIR spectroscope (Cary 630 FTIR Agilent), Bruker HCT ESI-IT mass spectrometer (Electro Spray Ionization-Ion Trap) and Waters LCT XE ESI-TOF mass spectrometer (Electro Spray Ionization-Time of flight), SEM-EDX ZEISS EVO MA 10, and supporting glassware.

\section{Synthesis of the 4-vinylpyridine oligomer}

An aliquot of $30.7 \mathrm{~mL}$ 4-vinylpyridine monomer was mixed with $75 \mathrm{~mL}$ methanol, $75 \mathrm{~mL}$ distilled water, and $28.3 \mathrm{~mL} \mathrm{H}_{2} \mathrm{O}_{2}(0.25 \mathrm{~mol})$ in a triple neck flask and refluxed at $80^{\circ} \mathrm{C}$ for $10 \mathrm{~h}$ in an oil bath. After the completion of the reaction, the solvent was removed using a rotary evaporator and the product was transferred into a dark bottle and kept in a refrigerator.

\section{Characterization of functional groups and determination of molecular weight}

The functionality of the monomer and oligomer produced was identified using Fourier transform infrared (FTIR) spectroscopy, and the molecular weight distribution of the oligomer was determined using mass spectrometry (MS).

\section{Determination of the activity as a corrosion inhibitor}

\section{a. Weight loss method (wheel test)}

Fifteen Duran glass bottles with a volume of $250 \mathrm{~mL}$ were filled with $175 \mathrm{~mL}$ brine solution into each of the bottles. A certain volume of $10,000 \mathrm{mg} \mathrm{L}^{-1}$ oligomer solution was added from a micropipette to every three bottles in order to obtain the oligomer concentrations of 0 (blank solution), 25, 50,100, and $150 \mathrm{mg} \mathrm{L}^{-1}$. The solutions were saturated with $\mathrm{CO}_{2}$ gas by purging them with the gas for 45 minutes. A mild steel coupon with a known mass was placed in each bottle, and the flow of $\mathrm{CO}_{2}$ gas was cautiously stopped to ensure no oxygen entered the bottle. The bottles were immediately sealed tightly and then placed in a wheel oven for 24 hours at a temperature of $50^{\circ} \mathrm{C}$. After completion of the experiment, the bottles 
were taken out from the wheel oven and the coupons were removed followed by cleaning with Clarke's solution (a solution containing 2\% $\mathrm{Sb}_{2} \mathrm{O}_{3}$ and $5 \% \quad \mathrm{SnCl}_{2}$ dissolved in concentrated $\mathrm{HCl}$ ) for 45 seconds to remove the corrosion products from the surface. The coupons were washed with water and ethanol, and finally dried to remove the solvents. The dried coupons were weighed to determine the weight loss, from which the corrosion rate and the inhibition efficiency $(\% P)$ were calculated [12].

\section{b. Electrochemical methods}

The electrochemical evaluation of the inhibitor activity was carried out using EIS and Tafel methods, using the experimental circuit depicted in Figure 1.

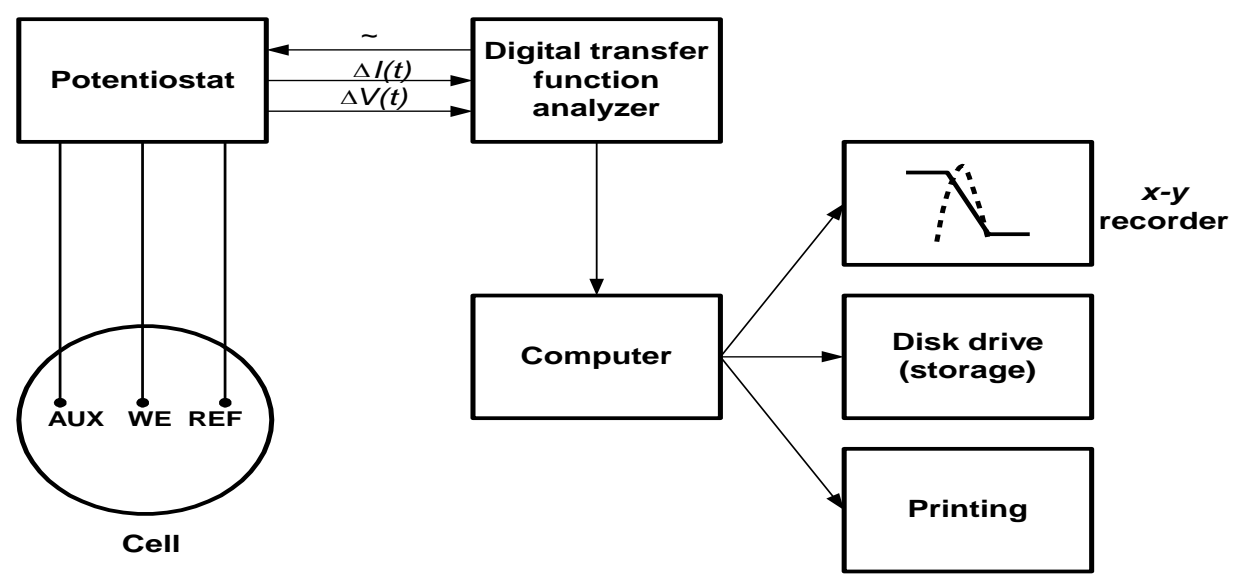

Figure 1. Schematic of the electrode circuit for the electrochemical method.

Figure 1 shows a typical electrochemical corrosion test cell consisting of three electrodes (reference electrode, counter electrode, and test electrode) submerged in an electrolyte, with a potentiostat, power supply, ammeter and electrometer. To commence the EIS experiment, the glass cell connected to counter, reference and working electrodes was filled with $100 \mathrm{~mL}$ of the corrosive solution and placed on a hot plate. The circuit was connected to the Voltalab instrument and the water bath was turned on and adjusted to the experimental temperature. The $\mathrm{CO}_{2}$ was then purged into the chamber (approximately 45 minutes) to saturate the corrosive solution and then the flow rate of $\mathrm{CO}_{2}$ was maintained at $100 \mathrm{~mL} \mathrm{m^{-1 }}$ during the measurement. The EIS measurements were conducted at 30, 50, and $70^{\circ} \mathrm{C}$, and the results are presented as a Nyquist plot, which is a plot in the real impedance $\left(Z_{\mathrm{r}}\right)$ and imaginary impedance $\left(Z_{\mathrm{i}}\right)$ coordinates. From the $Z_{\mathrm{r}}$ values in the curve, the charge transfer resistance $\left(R_{\mathrm{ct}}\right)$ and the percent of protection $(\% P)$ were calculated using Equation (1) and Equation (2), respectively.

$$
R_{\mathrm{ct}}=\left(R_{\mathrm{ct}}+R_{\mathrm{S}}\right)-R_{\mathrm{S}}
$$




$$
\% P=\frac{R_{\mathrm{ct}_{\mathrm{i}}}-R_{\mathrm{ct}_{0}}}{R_{\mathrm{ct}_{\mathrm{i}}}} \cdot 100 \%
$$

Where

$R_{\mathrm{S}}$ : solution resistance $\left(\Omega \mathrm{cm}^{-2}\right)$,

$R_{\mathrm{ct}_{0}}$ : charge transfer resistance of blank $\left(\Omega \mathrm{cm}^{-2}\right)$

$R_{\mathrm{ct}_{\mathrm{i}}}$ : charge transfer resistance of inhibitor $\left(\Omega \mathrm{cm}^{-2}\right)$

The experiments for measuring the corrosion rate using the Tafel method were carried out using the blank solution and the solution containing $150 \mathrm{mg} \mathrm{L}^{-1}$ oligomer. The experiments were undertaken at different temperatures of 30,50 and $70^{\circ} \mathrm{C}$, respectively. The circuit was connected to a Voltalab device and the DC potential was set at $200 \mathrm{mV}$. From the measurement, the following electrochemical parameters were obtained: the corrosion potential $\left(E_{\text {corr }}\right)$, the anodic Tafel constant $\left(\beta_{\mathrm{a}}\right)$, the cathodic Tafel constant $\left(\beta_{\mathrm{c}}\right)$, and the current density value $\left(i_{\text {corr }}\right)$. Protection percentage $(\% P)$ was calculated using Equation 3:

$$
\% P=\frac{i_{\text {corr }_{0}}-i_{\text {corri }_{i}}}{i_{\text {corr }_{i}}} \cdot 100 \%
$$

where:

$i_{\text {corr }}:$ the current density value in the blank solution,

$i_{\text {corr }}:$ the current density value in the inhibitor solution

$\% P$ : Protection percentage.

\section{Surface analysis}

To obtain a visual image of the surface, an untreated (original) coupon, a coupon immersed in the corrosive solution without an inhibitor, and a coupon immersed in the corrosive solution containing the inhibitor with a concentration of $150 \mathrm{mg} \mathrm{L}^{-1}$ were characterized using SEM.

\section{Results and Discussion}

In this research, the product is an orange viscous liquid but it appears to be less viscous than the product obtained using $\mathrm{H}_{2} \mathrm{O}_{2}$ at a concentration of $0.33 \mathrm{M}$ reported in the previous study [12].

\section{FTIR analysis}

The FTIR spectra of the 4-VP monomer and that of 4-VP oligomer synthesized are presented in Figure 2. 


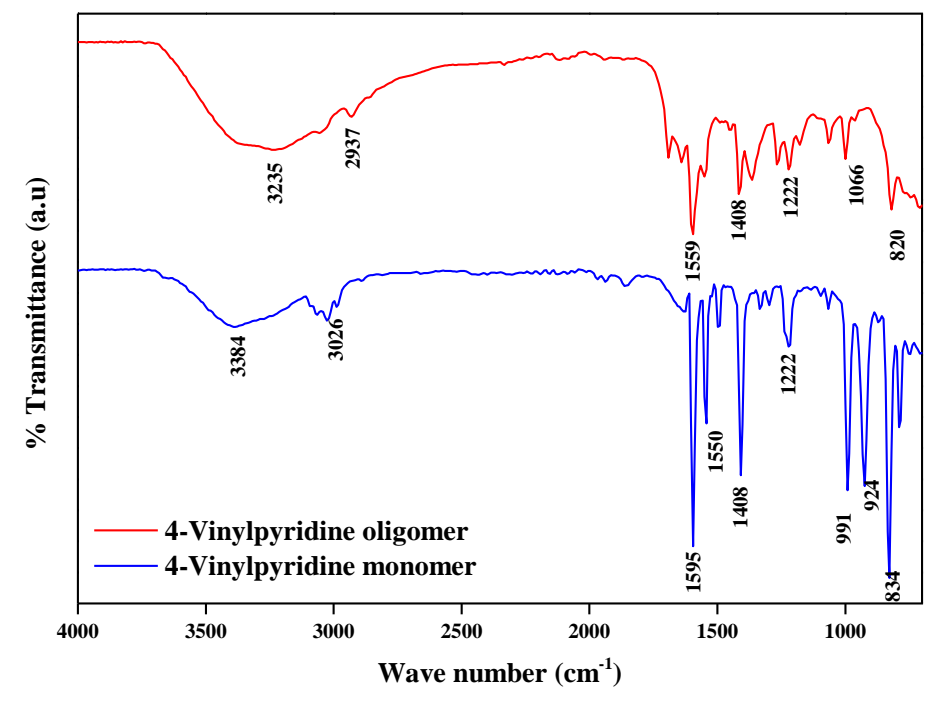

Figure 2. FTIR spectra of 4-VP monomer and 4-VP oligomer.

As can be seen in Figure 2, the two spectra display a similar general pattern, although the absorption bands in the spectrum of the monomer are more intense than those in the spectrum of the oligomer. The presence of the $-\mathrm{OH}$ functional group is presented by the absorption band centered at $3384 \mathrm{~cm}^{-1}$ in the spectrum of the monomer and at $3235 \mathrm{~cm}^{-1}$ in the spectrum of the oligomer. The absorption band at a wave number of $1595 \mathrm{~cm}^{-1}(1650-$ $1450 \mathrm{~cm}^{-1}$ ) is associated with the stretching vibration of the $\mathrm{C}=\mathrm{C}$ and $\mathrm{C}=\mathrm{N}$ functional groups in the aromatic ring, and the bands at wavenumbers of $1408 \mathrm{~cm}^{-1}$ and $1222 \mathrm{~cm}^{-1}$ result from vibrations of the $\mathrm{C}-\mathrm{N}$ functional group, which is a characteristic functional group of vinylpyridine. The absorption bands at $1000-650 \mathrm{~cm}^{-1}$ are fingerprint regions associated with $\mathrm{C}=\mathrm{C}-\mathrm{H}, \mathrm{Ar}-\mathrm{H}$ bending.

\section{Molecular Weight Determination}

The MS spectrum of the oligomer synthesized is presented in Figure 3, showing that the sample is composed of a series of components with different molecular weights.

As can be seen in Table 2, the molecular weights of the components range from 122 to 994, with variation in relative intensity from 100 to $<10 \%$ and with the tendency of decreasing intensity with increased relative intensity. This variation in molecular weight and relative intensity indicates that polymerization undertaken under the reaction conditions used led to production of oligomers with varied numbers of monomer and also in different relative quantities. In this regard, the experimental results obtained demonstrate that the most abundant constituent of the sample is the oligomer with $m / z=451$, while the oligomers with $\mathrm{m} / \mathrm{z}$ from 693 to 994 exist as minor components with respect to their relative intensities which are less than $10 \%$.

The molecular weight distribution of the components in the sample and the relative intensity of each component are compiled in Table 1. 


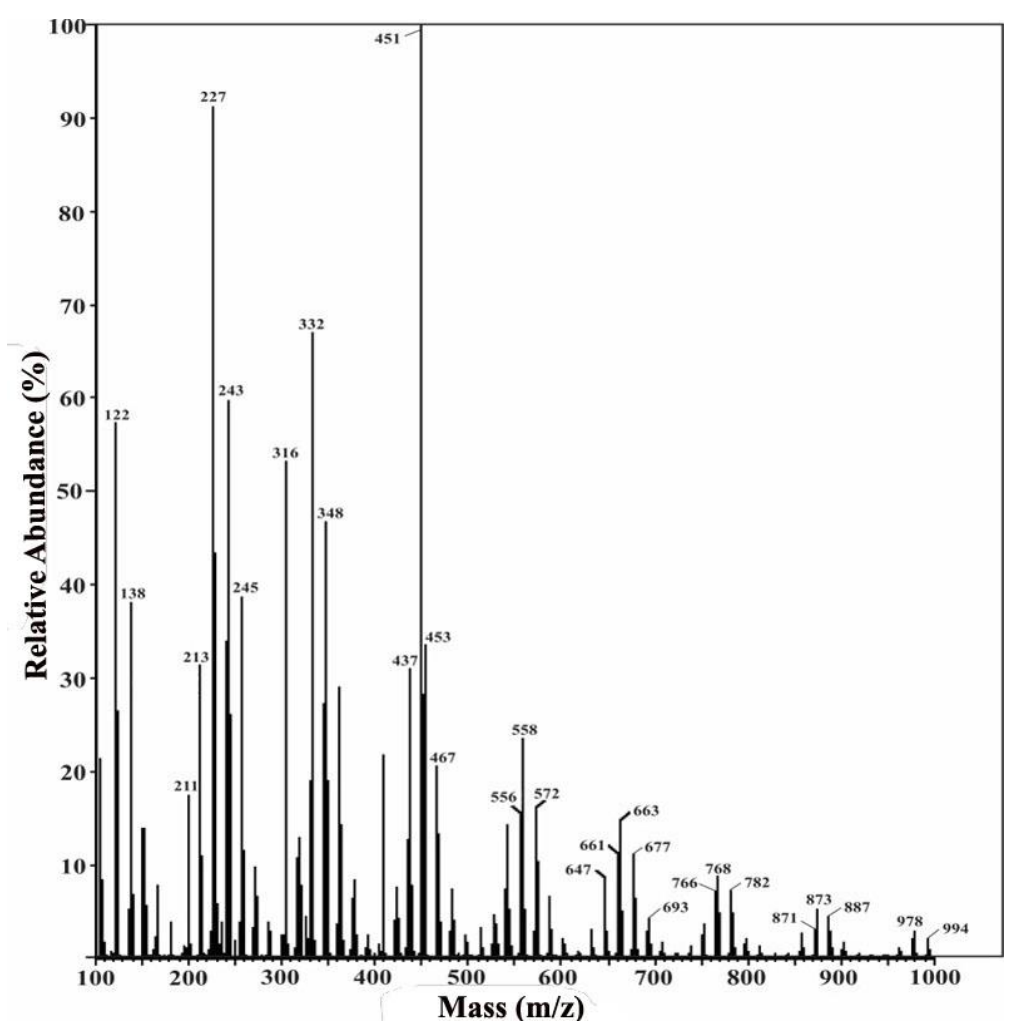

Figure 3. The MS spectrum of 4-VP oligomer synthesized.

Table 1. Molecular weight $(\mathrm{m} / \mathrm{z})$ and relative intensity of the components of the sample synthesized.

\begin{tabular}{cccccc}
\hline No. & $\boldsymbol{m} / \boldsymbol{z}$ & Relative intensity $(\boldsymbol{\%})$ & No. & $\boldsymbol{m} / \boldsymbol{z}$ & Relative intensity $(\%)$ \\
\hline 1 & 122 & 58 & 16 & 558 & 24 \\
2 & 138 & 38 & 17 & 572 & 17 \\
3 & 211 & 28 & 18 & 647 & $<10$ \\
4 & 213 & 32 & 19 & 661 & 12 \\
5 & 227 & 91 & 20 & 663 & 15 \\
6 & 243 & 60 & 21 & 677 & $<10$ \\
7 & 245 & 39 & 22 & 693 & $<10$ \\
8 & 316 & 53 & 23 & 766 & $<10$ \\
9 & 332 & 24 & 768 & $<10$ \\
10 & 348 & 67 & 25 & 782 & $<10$ \\
11 & 437 & 47 & 26 & 871 & $<10$ \\
12 & 451 & 31 & 27 & 873 & $<10$ \\
13 & 453 & 100 & 28 & 887 & $<10$ \\
14 & 467 & 34 & 29 & 978 & $<10$ \\
15 & 556 & 21 & 30 & 994 & \\
\hline
\end{tabular}


In addition to the number of monomer units, another factor that leads to variation in molecular weight of oligomeric compounds is the difference in the end groups of the compounds. In the sample investigated in this study, the possible end groups of the constituents are presented in Table 2.

Table 2. Mass of the O(4-VP) end group for some combinations [12].

\begin{tabular}{cccccc}
\hline End Groups $\rightarrow$ & $\mathbf{C}=\mathbf{C}$ & $\mathbf{H}$ & $\mathbf{O H}$ & $\mathbf{C H}_{\mathbf{3}}$ & $\mathbf{O C H}_{\mathbf{3}}$ \\
\hline Mass $\downarrow$ & $(\boldsymbol{m}=-\mathbf{1})$ & $(\boldsymbol{m}=\mathbf{1})$ & $(\boldsymbol{m}=\mathbf{1 7})$ & $(\boldsymbol{m}=\mathbf{1 5})$ & $(\boldsymbol{m}=\mathbf{3 1})$ \\
\hline $\mathrm{H}(m=1)$ & 0 & 2 & & & \\
$\mathrm{OH}(m=17)$ & 16 & 18 & 34 & & \\
$\mathrm{CH}_{3}(m=15)$ & 14 & 16 & 32 & 30 & \\
$\mathrm{OCH}_{3}(m=31)$ & 30 & 32 & 48 & 46 & 62 \\
\hline
\end{tabular}

The contribution of the two aforementioned factors to the molecular weight of the oligomer is given by the Equation (4):

$$
M w \text { of oligomer }=n \cdot 105+m+1
$$

where:

$n$ : number of monomer units,

$m$ : mass of the end group, 1 is the mass of one proton (attached during ionization).

As an example, detection of the component with $\mathrm{m} / \mathrm{z}=122$ indicates that the monomer ( $n=1$ and $M w=105 \mathrm{~g} / \mathrm{mol}$ ) has undergone the change in the end groups to $\mathrm{OH}$ and $\mathrm{CH}_{3}$. Similarly, the detection of component with $\mathrm{m} / z=138$ indicates the change of end groups of the monomer to the combination of $\mathrm{OCH}_{3}$ and $\mathrm{CH}_{3}$. These changes of the monomer and oligomer are illustrated in Figure 4.

Taking the number of monomer units and variation of the end groups into account, the composition of the sample is summarized in Table 3. Overall, the MS profiles of the sample indicate that the sample is a mixture of monomeric species and polymeric species made of 2 to 9 monomer units. In the previous research [12], the synthesis of 4-VP using $0.33 \mathrm{M} \mathrm{H}_{2} \mathrm{O}_{2}$ as the initiator was reported to produce the products with molecular weights in the range of $200-2200 \mathrm{~g} / \mathrm{mol}$ which are equivalent to $n=2-22$. The results of this previous study and the present study justify the important role the concentration of $\mathrm{H}_{2} \mathrm{O}_{2}$ initiator in governing the degree of polymerization. 


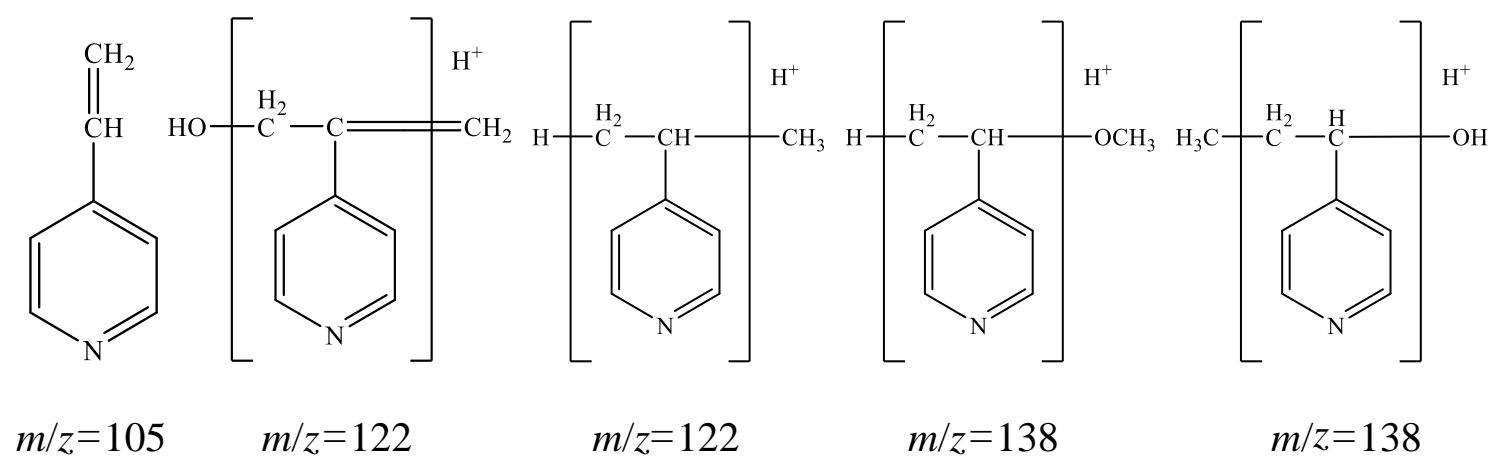

(a). 4-Vinylpyridine monomer<smiles>Cc1cnccc1C(C)C(C)C</smiles>

$m / z=227$

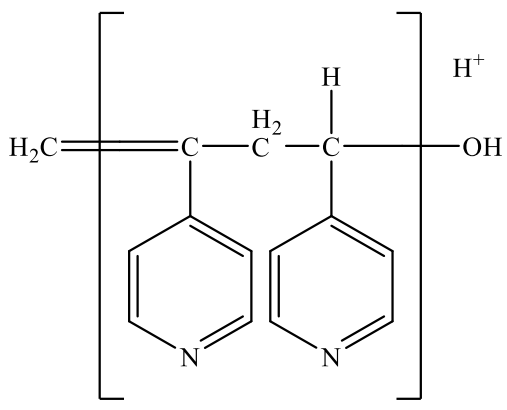

$m / z=227$

(b) 4-Vinylpyridine dimer

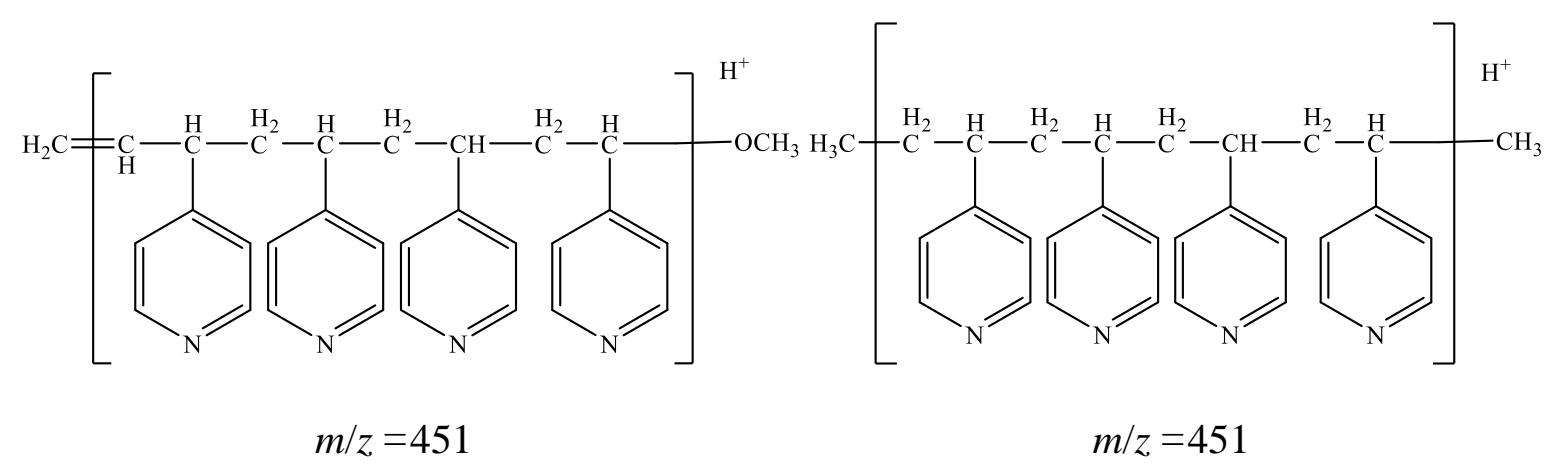

(c) 4-Vinylpyridine tetramer

Figure 4. Examples of structures of (a) 4-vinylpyridine monomer $(n=1)$ with various molecular weights $(\mathrm{m} / \mathrm{z})$ of 105, 122 and 138, (b) 4- vinylpyridine dimer $(\mathrm{n}=2)$ with $\mathrm{m} / \mathrm{z}=227$, and (c) 4-vinylpyridine tetramer $(n=4)$ with $m / z=451$. 
Table 3. Composition of the synthesized sample.

\begin{tabular}{cc}
\hline Numbers of monomer units $(\boldsymbol{n})$ & Molecular weight $(\boldsymbol{m} / \boldsymbol{z})$ \\
\hline 1 & $(122)$ and $(138)$ \\
2 & $(211),(213),(227),(243)$, and $(245)$ \\
3 & $(316),(332)$, and $(348)$ \\
4 & $(437),(451),(453)$, and $(467)$ \\
5 & $(556),(558)$, and $(572)$ \\
6 & $(647),(661),(663),(677)$, and $(693)$ \\
7 & $(766),(768)$, and $(782)$ \\
8 & $(871),(873)$, and $(887)$ \\
9 & $(978)$ and $(994)$ \\
\hline
\end{tabular}

Taking the relative intensities into account, the results obtained demonstrate that the main components of the sample are oligomers with $n=2$ (dimer) to $n=4$ (tetramer). In addition, the existence of oligomers with the same number of monomer units $(n)$ but with different molecular weights should be acknowledged.

\section{Corrosion Inhibition Study}

\section{A. Wheel Test Results}

In this study, the wheel test was conducted as a screening test to determine whether the oligomer synthesized can function as a corrosion inhibitor or not. An blank experiment was similarly conducted without an inhibitor. The results are shown in Table 4.

The results presented in Table 4 clearly indicate that without an inhibitor, the sample (mild steel) is very prone to corrosion, as suggested by the corrosion rate observed. The results also indicate that the $\mathrm{O}(4-\mathrm{VP})$ synthesized exhibits the ability to suppress the corrosion as suggested by the decreased corrosion rate or increased protection percentage. In addition, the inhibitor concentration was found to enhance the ability of the inhibitor to suppress the corrosion of the sample.

Table 4. The results of the wheel test using $\mathrm{O}(4-\mathrm{VP})$ as a corrosion inhibitor at $50^{\circ} \mathrm{C}$.

\begin{tabular}{ccccc}
\hline $\begin{array}{c}\text { Inhibitor concentration } \\
\left(\mathbf{m g ~ L}^{-\mathbf{1}}\right)\end{array}$ & $\begin{array}{c}\text { Weight loss } \\
(\mathbf{g r a m})\end{array}$ & $\begin{array}{c}\text { Coupon area } \\
\left.\mathbf{( c m}^{\mathbf{2}}\right)\end{array}$ & $\begin{array}{c}\text { Corrosion rate } \\
(\mathbf{m m p y})\end{array}$ & $\boldsymbol{\% P}$ \\
\hline 0 & 0.0148 & 5.1474 & 1.33 & - \\
25 & 0.0092 & 5.0568 & 0.85 & 36.72 \\
50 & 0.0093 & 5.4378 & 0.80 & 40.51 \\
100 & 0.0083 & 5.2200 & 0.74 & 44.70 \\
150 & 0.0076 & 5.2050 & 0.68 & 49.21 \\
\hline
\end{tabular}




\section{B. EIS Results}

To evaluate the inhibition activity of the O(4-VP) synthesized, EIS measurements were carried out using the same inhibitor concentrations as in the wheel test but at various temperatures.
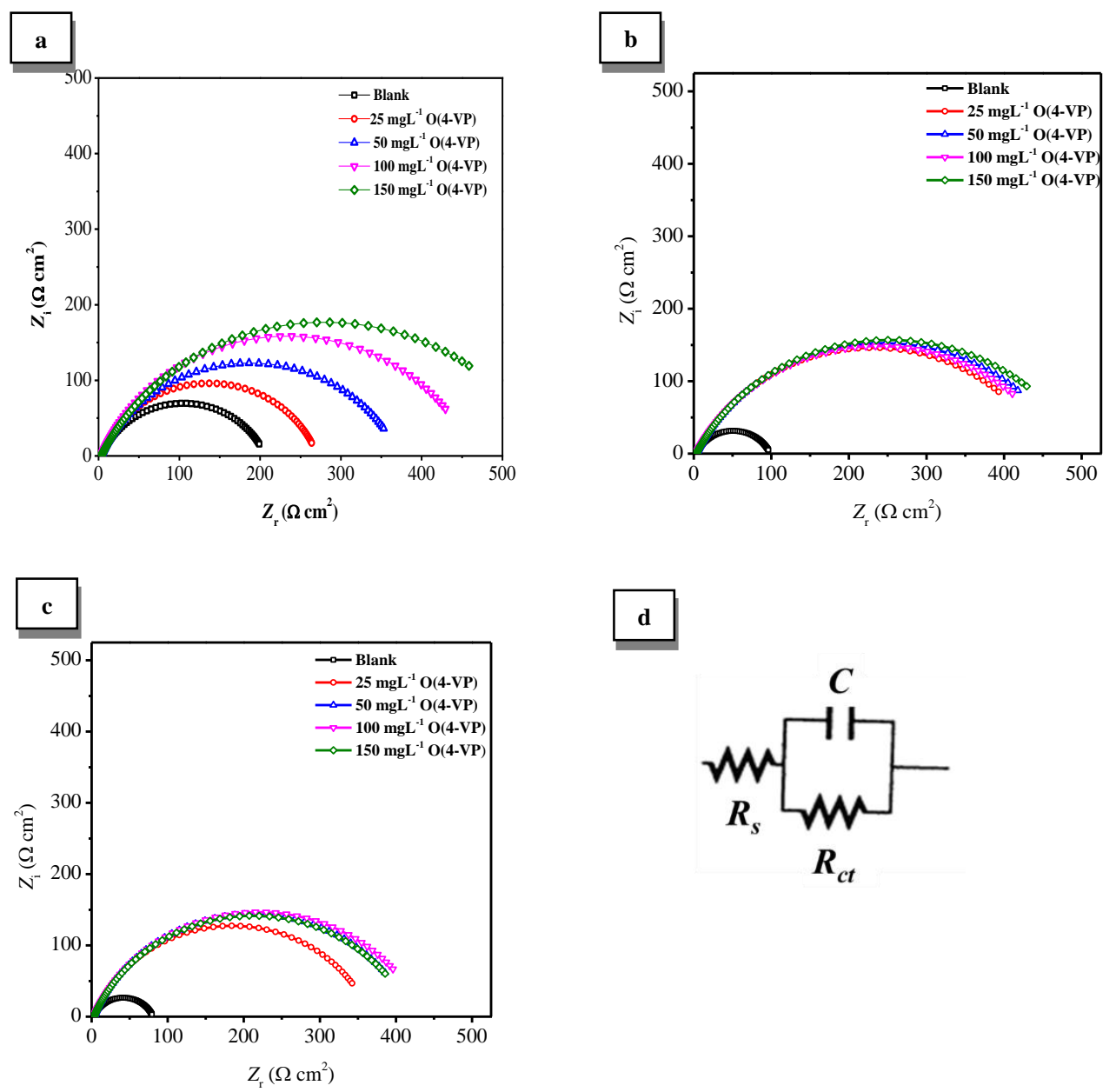

Figure 5. The Nyquist plots of blank and $\mathrm{O}(4-\mathrm{VP})$ with various concentrations at temperatures (a) 30 , (b) 50, (c) $70^{\circ} \mathrm{C}$; (d) the equivalent circuit model for the inhibitor studied.

The EIS technique was applied in this study since it has been acknowledged as a good technique to determine the interface processes that occur upon inhibitor adsorption on a metal surface in a $\mathrm{CO}_{2}$ environment [4]. The EIS data are expressed as Nyquist plots which are created by plotting real impedance $\left(Z_{\mathrm{r}}\right)$ against imaginary impedance $\left(Z_{\mathrm{i}}\right)$ as shown in Figure 5.

In Figure 5, the minimum value of $Z_{\mathrm{r}}$ indicates the value of the solution resistance $\left(R_{\mathrm{s}}\right)$ and the maximum value of $Z_{\mathrm{r}}$ is the sum of the charge transfer resistance $\left(R_{\mathrm{ct}}\right)$ and $R_{\mathrm{s}}$. Therefore, $R_{\mathrm{ct}}=\left(R_{\mathrm{ct}}+R_{\mathrm{s}}\right)-R_{\mathrm{s}}$. The maximum value of $Z_{\mathrm{r}}$ is linearly proportional with the percent of protection or inversely proportional to the corrosion rate, so it can also be seen that the higher the temperature, the higher the corrosion rate. Data in Figure 5 indicate that 
for the blank experiment, the value of $Z_{\mathrm{r}}$ decreases with increasing temperatures, implying that in the absence of an inhibitor, the higher the temperature, the higher the corrosion rate. The data from EIS measurements values, namely, $R_{\mathrm{s}}, R_{\mathrm{ct}}$, and $\% P$ at different concentrations and temperatures are summarized in Table 5. The percentage of protection was calculated using Equation 2 presented above.

Table 5. Parameters obtained from the impedance spectra analysis and percentage protection by $\mathrm{O}(4-\mathrm{VP})$.

\begin{tabular}{ccccc}
\hline $\begin{array}{c}\text { Concentration of } \\
\mathbf{O}(\mathbf{4 - V P})\left(\mathbf{m g ~ L}^{-\mathbf{1}}\right)\end{array}$ & $\begin{array}{c}\text { Temperature } \\
\left({ }^{\circ} \mathbf{C}\right)\end{array}$ & $\begin{array}{c}\boldsymbol{R}_{\mathbf{s}} \\
\left(\mathbf{\Omega} \mathbf{c m}^{\mathbf{2}}\right)\end{array}$ & $\begin{array}{c}\boldsymbol{R}_{\mathbf{c t}} \\
\left(\mathbf{\Omega} \mathbf{c m}^{\mathbf{2}}\right)\end{array}$ & $\boldsymbol{\%} \boldsymbol{P}$ \\
\hline 0 & & 3.398 & 199.802 & - \\
25 & & 2.640 & 239.160 & 16.45 \\
50 & 30 & 3.474 & 264.026 & 24.32 \\
100 & & 3.298 & 366.202 & 45.43 \\
150 & & 3.287 & 456.913 & 56.36 \\
& & 3.210 & 92.210 & - \\
0 & & 3.240 & 450.360 & 79.52 \\
50 & 50 & 3.200 & 477.300 & 80.68 \\
100 & & 3.213 & 466.387 & 80.22 \\
150 & & 3.227 & 495.473 & 86.46 \\
\hline 0 & & 2.753 & 75.137 & - \\
25 & & 2.893 & 361.400 & 79.20 \\
50 & & 2.909 & 415.791 & 81.92 \\
100 & 70 & 2.937 & 431.263 & 82.57 \\
150 & & 2.995 & 415.805 & 81.92 \\
\hline
\end{tabular}

Table 5 shows the effect of inhibitor addition with the concentrations from 25 to $150 \mathrm{mg} \mathrm{L}^{-1}$ on $R_{\mathrm{ct}}$ and $\% P$. In general, it is acknowledged that the higher the $R_{\mathrm{ct}}$ value, the lower the corrosion rate or the higher the protection percentage $(\% P)$. For the experiments carried out at $30^{\circ} \mathrm{C}$, this general relationship is observed. For the experiments carried out at 50 and $70^{\circ} \mathrm{C}$, the results are not completely consistent with the general relationship, however the differences are not significant, and most likely due to measurement error. The tendency of increased percentage of protection with an increase in the inhibitor concentration as observed in Table 5 suggest that with increase in inhibitor concentration, the protective layer on the surface of the sample was enhanced to prevent the corrosion attack. The results in Table 5 also display the tendency that the higher the temperature and concentration, the higher the protection exhibited by the inhibitor, suggesting that the $\mathrm{O}(4-\mathrm{VP})$ inhibitor was adsorbed onto the mild steel surface through chemisorption $[13,17,18]$. 


\section{Tafel Plot Results}

Another electrochemical method applied to study the ability of the oligomer to inhibit corrosion of the sample is the potentiodynamic polarization (Tafel Plot) method based on recording polarization curves. The experiments were carried out using the inhibitor at a fixed concentration of $150 \mathrm{mg} \mathrm{L}^{-1}$ at various temperatures. The polarization curves obtained were presented in Figure 6.
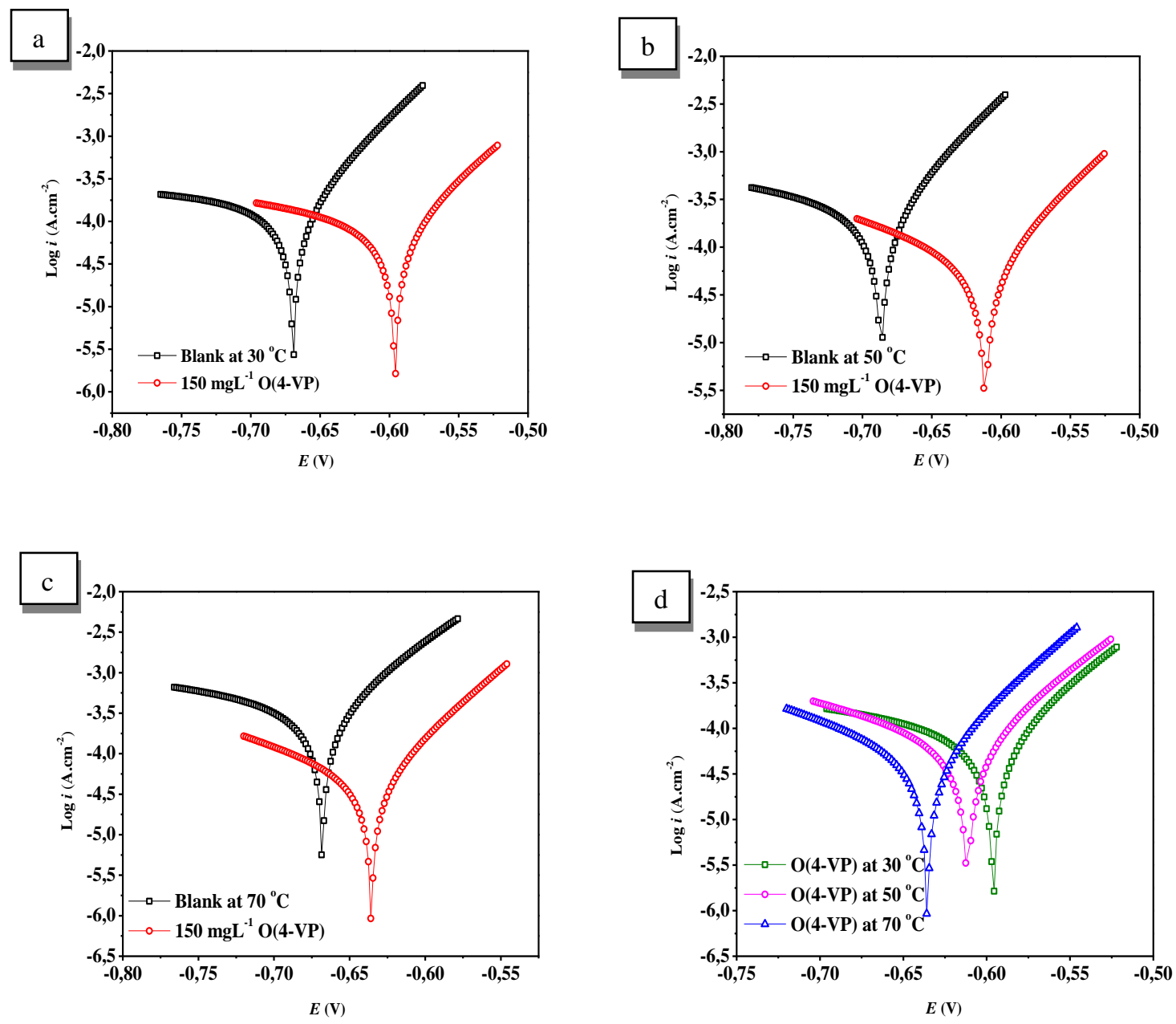

Figure 6. Polarization curves of the blank solution and a solution containing $150 \mathrm{mg} \mathrm{L}^{-1}$ of $\mathrm{O}\left(4-\mathrm{VP}\right.$ ) inhibitor at temperatures (a) 30 , (b) 50 , (c) $70^{\circ} \mathrm{C}$ and (d) $150 \mathrm{mg} \mathrm{L}^{-1}$ of O(4-VP) inhibitor at various temperatures.

The polarization curves were then extrapolated to obtain electrical quantities related to the corrosion process, including the corrosion potential $\left(E_{\text {corr }}\right)$, polarization resistance $\left(R_{p}\right)$, anodic Tafel constant $\left(\left(\beta_{\mathrm{a}}\right)\right.$, cathodic Tafel constant $\left(\beta_{\mathrm{c}}\right)$, and corrosion density value $\left(i_{\text {corr }}\right)$. The results are shown in Table 6. 
Table 6. Data from polarization curve extrapolation.

\begin{tabular}{cccccccc}
\hline Composition & $\begin{array}{c}\text { Temperature } \\
\left({ }^{\circ} \mathbf{C}\right)\end{array}$ & $\begin{array}{c}\boldsymbol{E}_{\mathbf{c o r r}} \\
(\mathbf{m V})\end{array}$ & $\begin{array}{c}\boldsymbol{I}_{\mathbf{c o r r}} \\
\left(\boldsymbol{\mu} \mathbf{A} \mathbf{c m}^{-\mathbf{2}}\right)\end{array}$ & $\begin{array}{c}\boldsymbol{\beta}_{\mathbf{a}} \\
(\mathbf{m V})\end{array}$ & $\begin{array}{c}\boldsymbol{\beta} \mathbf{c} \\
(\mathbf{m V})\end{array}$ & $\begin{array}{c}\boldsymbol{C R} \\
(\mathbf{m m p y})\end{array}$ & $\begin{array}{c}\boldsymbol{\%} \boldsymbol{P} \\
(\boldsymbol{\%})\end{array}$ \\
\hline Blank (B) & 30 & -669.449 & 162.297 & 66.9 & 807.1 & 1.6457 & - \\
$\mathrm{B}+\mathrm{O}(4-\mathrm{VP})$ & & -595.976 & 99.788 & 79.7 & 433.9 & 1.0118 & 38.51 \\
B & 50 & -686.665 & 268.757 & 75.6 & 443.7 & 2.7253 & - \\
$\mathrm{B}+\mathrm{O}(4-\mathrm{VP})$ & & -611.411 & 84.211 & 80.7 & 249.8 & 0.8539 & 68.66 \\
B & 70 & -668.082 & 413.143 & 83.5 & 439.7 & 4.1894 & - \\
$\mathrm{B}+\mathrm{O}(4-\mathrm{VP})$ & & -635.635 & 50.487 & 63.6 & 162.5 & 0.5110 & 87.77 \\
\hline
\end{tabular}

Data in Table 6 clearly indicate that the protection percentage is higher at elevated temperatures, which is in agreement with the results obtained using the EIS method, and confirms that the inhibitor is chemically adsorbed onto the surface of the samples. The results obtained in this study are in good agreement with the results reported by others regarding the temperature effect $[19,20]$.

\section{Scanning Electron Microscopy (SEM)}

Since corrosion is a surface process, surface morphology of a sample provides visual information on how good a corrosion inhibitor protects the sample in a corrosive environment. For this reason, the SEM technique was applied to characterize three mild steel samples, i.e., the original/untreated sample, the sample exposed to the corrosive solution for $24 \mathrm{~h}$, and the sample exposed to the corrosive solution containing the inhibitor for $24 \mathrm{~h}$. The results are presented in Figure 7.

As can be seen in Figure 7, the surface of the original sample (A) is smooth without any corrosion products, quite in contrast to the surface of the sample treated without an inhibitor (B). As can be seen, the surface of this unprotected sample is severely damaged, with very evident corrosion product covering the surface of the sample. In contrast to the unprotected sample, the micrograph of the sample treated in the presence of the inhibitor (C) shows that the surface was well protected by the inhibitor applied, implying the formation of an effective protective layer on the metal surface. 

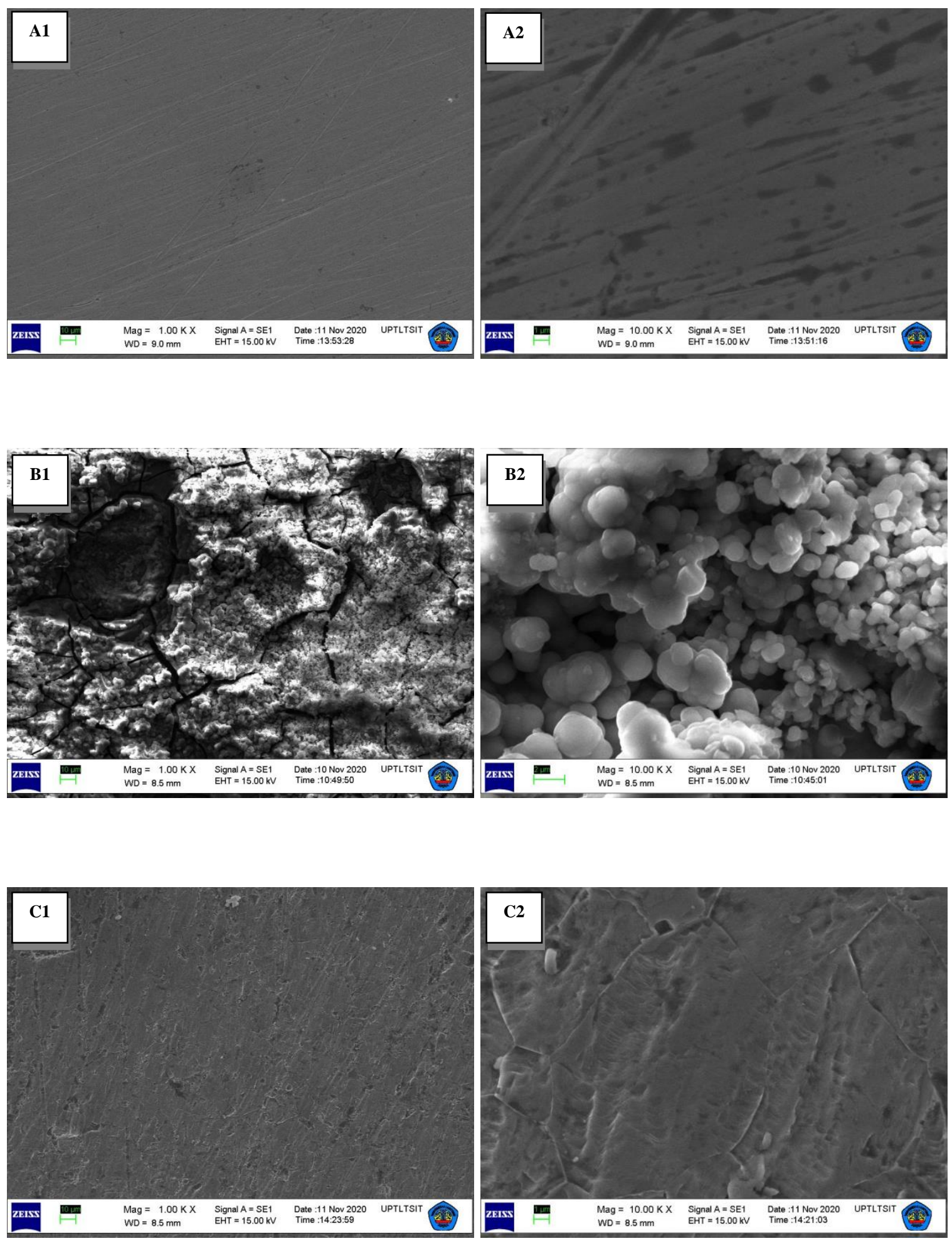

Figure 7. SEM micrographs of untreated mild steel (A), mild steel after 24 hours of immersion in the corrosive solution without an inhibitor (B), and mild steel in the corrosive solution containing the inhibitor $(\mathrm{C})$. 


\section{Conclusion}

Based on the data obtained in this study, the following conclusions were drawn:

1. The results of MS analysis show that the $\mathrm{O}(4-\mathrm{VP})$ synthesized has molecular weights within 100-900 m/z which are equivalents of 1-9 monomer units, where the oligomers with $n=2-4$ are the primary constituents.

2 . The corrosion inhibition activity assays by the weight loss method and electrochemical methods demonstrated that the oligomer exhibits activity as a corrosion inhibitor.

3. The results indicate that a higher protection percentage was achieved at a higher concentration and temperature, suggesting that the inhibitor was chemically adsorbed onto the surface of the sample.

4. The highest protection percentage of $87.8 \%$ was achieved using the inhibitor at a concentration of $150 \mathrm{mg} \mathrm{L}^{-1}$ and a temperature of $70^{\circ} \mathrm{C}$.

5. Surface analysis using SEM suggests the formation of a protective layer which effectively covers the entire surface of the sample.

\section{Acknowledgements}

The authors would like to sincerely acknowledge the Ministry of Research Technology and National Research and Innovation Agency of the Republic of Indonesia for financial support provided through the Scheme of Penelitian Dasar 2019" Research Grant, Contract Number 065/SP2H/LT/DRPM/2019.

\section{References}

1. M.A.J. Mazumder, H.A. Al-Muallem, M. Faiz and S.A. Ali, Design and synthesis of a metal class of inhibitors for mild steel corrosion in acidic carbon dioxide-saturated saline media, Corros. Sci., 2014, 87, 187-198. doi: 10.1016/j.corsci.2014.06.026

2. M. Tourabi, K. Nohair, A. Nyassi, B. Hammouti, C. Jama and F. Bentis, Thermodynamic characterization of metal dissolution and inhibitor adsorption processes in mild steel / 3,5bis(3,4-dimethoxyphenyl)-4-amino-1,2,4-triazole / hydrochloric acid system, J. Mater. Environ. Sci., 2014, 5, 1133-1143.

3. V.S. Sasri, Green Corrosion Inhibitors: Theory and Practice, $1^{\text {st }}$ Ed., John Wiley \& Sons Inc., 2011, Canada, 310.

4. F. Farelas, M. Galicia, B. Brown, S. Nesic and H. Castaneda, Evolution of dissolution processes at the interface of carbon steel corroding in a $\mathrm{CO}_{2}$ environment studied by EIS, Corros. Sci., 2010, 52, 509-517. doi: 10.1016/j.corsci.2009.10.007

5. F.F. Eliyan and A. Alfantazi, Mechanisms of corrosion and electrochemical significance of metallurgy and environment with corrosion of iron and steel in bicarbonate and carbonate solutions - A Review, Corrosion, 2014, 70, 880-898. doi: 10.5006/1213

6. R.R. Annand, R.M. Hurd and N. Hackerman, Inhibition of acid corrosion by soluble monomer and polymer amines containing identical functional groups, J. Electrochem. Soc., 1965, 112, 144-148. 
7. O.R. Khalifa, I.A. Abdul Hamid, S.M. Mochtar and A.A. Kassab, Inhibiting effect of poly-4-vinylpyridine on the acid corrosion of copper, Asian J. Chem. 1993, 5, 749-754.

8. M.B.A. El-Khair, B. Mostafa, O.R. Khalifa, I.A. Abed-Hamid and A.M. Azzam, The corrosion inhibition of copper by benzimidazole, Corros. Prev. Control, 1987, 34, 152.

9. A. Chetouani, K. Medjahed, S.S. Al-Deyab, B. Hammouti, I. Warad, A. Mansri, A. Aouniti, Inhibition of corrosion of pure Iron by quaternized poly(4-vinylpyridine)-graftbromodecane in sulphuric acid, Int. J. Electrochem. Sci., 2012, 7, 6025-6043.

10. Y. Abed, Z. Arrar, B. Hammouti, M. Taleb, S. Kertit and A. Mansri, Poly(4vinylpyridine) and poly(4-vinylpyridine poly-3-oxide ethylene) as corrosion inhibitors for Cu60-Zn40 in 0,5 $\mathrm{M} \mathrm{HNO}_{3}$, Anti-Corros. Methods Mater., 2001a, 48, 304-309. doi: 10.1108/EUM0000000005882

11. Y. Abed, B. Hammouti, F. Touhami, A. Aouniti, S. Kertit, A. Mansri and K. Elkacemi, Poly(4-vinylpyridine) (P4VP) as corrosion inhibitors of ARMCO iron in molar sulfuric acid solution, Bull. Electrochem., 2001b, 17, 105-110.

12. I. Ilim, A. Jefferson, W. Simanjuntak, M. Jeannin, Y.M. Syah, B. Bundjali and B. Buchari, Synthesis and characterization of oligomer 4-vinylpyridine as a corrosion inhibitor for mild steel in $\mathrm{CO}_{2}$ saturated brine solution, Indones. J. Chem., 2016, 16, 198-207. doi: 10.22146/ijc.21164

13. I. Ilim, S. Bahri, W. Simanjuntak, Y.M. Syah, B. Bundjali and B. Buchari, Performance of oligomer 4-vinylpiperidine as a carbon dioxide corrosion inhibitor of mild steel, $J$. Mater. Environ. Sci., 2017, 8, 2381-2390.

14. I. Ilim, Oligomers of vinylpyridine as corrosion inhibitors of mild steel in $3 \%$ brine solution saturated with carbon dioxide, Doctoral Dissertation, Institut Teknologi Bandung, 2017, 176.

15. I. Ilim, S. Bahri, R. Marjunus and W. Simanjuntak, The effect of initiator concentrations on corrosion inhibition activity of polymeric derivatives of 2-vinylpyridine, J. Phys.: Conf. Ser. 1751012094, 2021, 1-7. doi: 10.1088/1742-6596/1751/1/012094

16. E.F.V. Scriven, J.R. Stout, J.G. Keay and R. Murugan, US Patent Database IBM America, Really Industries, Inc. Indianapolis, 1995.

17. A. Popova, M. Christov, A. Vasilev and Chr. Girginov, Study of the temperature effect on electrochemical impedance spectra in presence of an inhibitor, Int. J. Corros. Scale Inhib., 2015, 4, 382-393. doi: 10.17675/2305-6894-2015-4-4-7

18. D.S. Z nad, Q.A. Jawad, M.A.M. Hussain, A. Mahal, L. Mohamed and A.A. AlAmiery, Adsorption, temperature and corrosion inhibition studies of a coumarin derivatives corrosion inhibitor for mild steel in acidic medium: gravimetric and theoretical investigations, Int. J. Corros. Scale Inhib., 2020, 9, 134-151. doi: 10.17675/2305-6894-2020-9-1-8

19. A. Zouitini, Y. Kandri Rodi, Y. Ouzidan, F. Ouazzani Chahdi, M. Mokhtari, I. AbdelRahman, E.M. Essassi, A. Aouniti, B. Hammouti and H. Elmsellem, Corrosion inhibition studies of new synthesized 1,4-dioctyl-6- methyl-1,4-dihydroquinoxaline-2,3- 
dione on mild steel in $1.0 \mathrm{M} \mathrm{HCl}$ solution using gravimetric and electrochemical techniques supported by theoretical DFT calculations, Int. J. Corros. Scale Inhib., 2019, 8, 225-240. doi: 10.17675/2305-6894-2019-8-2-5

20. W.N. Ahmaeed, A.N. Abd and A.A. Khadom, Corrosion inhibition effect of sodium iodide for mild steel in $1 \mathrm{M}$ hydrochloric acid: Gravimetrical and electrochemical studies, Int. J. Corros. Scale Inhib., 2019, 8, 1097-1111. doi: 10.17675/2305-68942019-8-4-17 